\title{
Sedentary behavior and subclinical atherosclerosis in African Americans: cross-sectional analysis of the Jackson heart study
}

Keith M. Diaz ${ }^{1 *}$, John N. Booth $\|^{2}$, Samantha R. Seals ${ }^{3}$, Steven P. Hooker ${ }^{4}$, Mario Sims ${ }^{5}$, Patricia M. Dubbert ${ }^{6}$, Paul Muntner' ${ }^{2}$ and Daichi Shimbo ${ }^{1}$

\begin{abstract}
Background: Previous studies have reported conflicting results as to whether an association exists between sedentary time and cardiovascular disease (CVD) risk among African Americans. These studies, however, were limited by lack of consideration of sedentary behavior in leisure versus non-leisure settings. To elucidate this relation, we investigated the associations of television (TV) viewing time and occupational sitting with carotid intima-media thickness (CIMT), a subclinical atherosclerosis measure, in a community-based sample of African Americans.
\end{abstract}

Methods: We studied 3410 participants from the Jackson Heart Study, a single-site, community-based study of African Americans residing in Jackson, MS. CIMT was assessed by ultrasonography and represented mean far-wall thickness across right and left sides of the common carotid artery. TV viewing time, a measure of leisure sedentary behavior, and occupational sitting, a measure of non-leisure sedentary behavior, were assessed by questionnaire.

Results: In a multivariable regression model that included physical activity and CVD risk factors, longer TV viewing time (2-4 h/day and $>4 \mathrm{~h} /$ day) was associated with greater CIMT (adjusted mean \pm SE difference from referent $[<2 \mathrm{~h} /$ day] of $0.009 \pm 0.008 \mathrm{~mm}$ for $2-4 \mathrm{~h} /$ day, and $0.028 \pm 0.009 \mathrm{~mm}$ for $>4 \mathrm{~h} /$ day; P-trend $=0.001$ ). In contrast, more frequent occupational sitting ('sometimes' and 'often/always') was associated with lower CIMT (adjusted mean \pm SE difference from referent ['never/seldom']: $-0.021 \pm 0.009 \mathrm{~mm}$ for 'sometimes', and $-0.018 \pm 0.008 \mathrm{~mm}$ for 'often/always'; P-trend $=0.042$ ).

Conclusions: Longer TV viewing time was associated with greater CIMT, while occupational sitting was associated with lower CIMT. These findings suggest the role of sedentary behaviors in the pathogenesis of CVD among African Americans may vary by whether individuals engage in leisure versus non-leisure sedentary behaviors.

Keywords: Sedentary, Television viewing, Atherosclerosis, African Americans, Carotid intima-media thickness

\footnotetext{
* Correspondence: kd2442@columbia.edu

${ }^{1}$ Department of Medicine, Center for Behavioral Cardiovascular Health,

Columbia University Medical Center, 622 West 168th Street, PH9-319, New

York, NY 10032, USA

Full list of author information is available at the end of the article
}

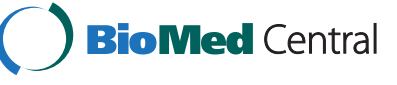

(c) 2016 Diaz et al. Open Access This article is distributed under the terms of the Creative Commons Attribution 4.0 International License (http://creativecommons.org/licenses/by/4.0/), which permits unrestricted use, distribution, and reproduction in any medium, provided you give appropriate credit to the original author(s) and the source, provide a link to the Creative Commons license, and indicate if changes were made. The Creative Commons Public Domain Dedication waiver (http://creativecommons.org/publicdomain/zero/1.0/) applies to the data made available in this article, unless otherwise stated. 


\section{Background}

African Americans have higher rates of cardiovascular disease (CVD), cancer, and a shorter life expectancy compared with whites [1-3]. Rates of obesity and diabetes are continuing to increase disproportionately among African Americans, raising concern racial disparities in health outcomes will continue to grow $[1,4,5]$. As a result, there is a need to identify modifiable risk factors in African Americans amenable to behavioral intervention.

Sedentary behaviors are independent, modifiable risk factors for CVD outcomes and mortality even among individuals who meet physical activity recommendations [6]. As such, sedentary behaviors are now thought to represent a unique aspect of an individual's overall physical activity profile and is no longer considered simply to be the extreme low end of the physical activity continuum [7]. The association between sedentary behaviors and CVD risk among African Americans, however, is unclear. Findings from the Coronary Artery Risk Development in Young Adults (CARDIA) study, National Health and Nutrition Examination Survey (NHANES), and Youth Risk Behavioral Survey have shown no association between sedentary behavior and CVD risk in African Americans [8-10]. More recently, sedentary behavior was associated with all-cause mortality, but not CVD mortality, among African Americans in the Southern Community Cohort Study [11]. Thus, there are conflicting findings regarding whether an association exists between sedentary behavior and CVD risk among African Americans. However, these previous studies were limited by relatively small sample sizes of African American participants and/ or lack of consideration of sedentary behavior in leisure versus non-leisure settings. Occupational sedentary time has been reported to have no association or a less adverse association with CVD risk than leisure-based sedentary behaviors including television (TV) viewing [12-15]. Thus, assessing overall sedentary behavior as a summary measure across leisure and non-leisure domains could obscure associations.

The purpose of this study was to examine the associations of TV viewing and occupational sitting with carotid artery intima-media thickness (CIMT), a measure of subclinical atherosclerosis, in a large community-based sample of African Americans enrolled in the Jackson Heart Study (JHS). We secondarily investigated the association of occupational standing time with CIMT.

\section{Methods}

\section{Study population}

The JHS is a large, single-site, population-based study of CVD among African Americans. Details of study design, recruitment, and data collection have been previously described [16-19]. Briefly, 5301 non-institutionalized African
American adults aged $\geq 21$ years were enrolled between 2000 and 2004 from the Atherosclerosis Risk in the Community (ARIC) site in Jackson, Mississippi (30 \%) and a regionally representative sample of urban and rural residents from the Jackson, Mississippi metropolitan tri-county region (Hinds, Madison and Rankin counties) that were randomly contacted (17\%), volunteers (22\%), or secondary family members $(31 \%)$. Data for the current cross-sectional analysis were collected during the baseline examination period which included an in-home interview and a clinical examination after an overnight fast. Information on sociodemographic characteristics, health behaviors, and medical history were collected via questionnaire during the in-home interview administered by trained African American interviewers. The clinical examination included blood sampling, anthropometric measurement, carotid ultrasonography, and blood pressure measurement to evaluate CVD risk factors. A pill bottle review of medications taken in the 2 weeks prior to the clinical examination was also conducted during the clinical examination. The median number of days between the in-home visit and the clinical examination was 13 days (25th-75th percentile: 7-26 days).

\section{Assessment of sedentary behaviors, standing time, and physical activity}

Sedentary behaviors, standing time, and physical activity were assessed using the JHS Physical Activity Survey, a 30-item questionnaire administered during the in-home interview that assesses physical activity over the past 12 months. The JHS Physical Activity Survey was adapted from modifications to the Baecke physical activity survey and was designed to improve physical activity assessment in African Americans [20]. TV viewing was assessed using the single-item question: 'During the past year, how often did you watch television?' with response options of 'Less than $1 \mathrm{~h}$ a week', 'At least $1 \mathrm{~h}$ a week, but less than $7 \mathrm{~h}$ a week', 'At least $1 \mathrm{~h}$ a day but less than $2 \mathrm{~h}$ a day', 'At least $2 \mathrm{~h}$ a day but less than $4 \mathrm{~h}$ a day', and 'four or more hours a day'. Occupational sitting was assessed using the singleitem question: 'When you are at work how often do you sit?' with response options of 'Never', 'Seldom', 'Sometimes', 'Often', and 'Always'. Time spent standing was also assessed in the occupational domain using the single-item question: 'When you are at work how often do you stand?' with response options of 'Never', 'Seldom', 'Sometimes', 'Often', and 'Always'. The assessment of TV viewing using a single, close-ended, quantitative response item has been validated against accelerometry $(r h o=0.22)$ and has good reproducibility $(r=0.75-0.78)[21,22]$. The assessment of occupational sitting using a single, close-ended response item has been validated against accelerometry supplemented with an activity $\log (\mathrm{rho}=0.63)$ and has moderate-to-good reproducibility (intraclass correlation coefficient $=0.74)[23]$. 
Leisure-time moderate to vigorous physical activity (MVPA) was assessed by a series of questions related to the yearly frequency and weekly duration of participation in up to three sports or exercise in the past year. Responses were converted to "minutes per week" for each sport or exercise reported and incorporated the number of months a participant partook in the sport or exercise (minutes/week $=[$ hours/week*60]" $[$ months in past year/12 months]) as previously described [24]. Each sport/exercise was assigned a metabolic equivalent of task (MET) value using the Compendium of Physical Activities [25]. Levels of leisure-time MVPA were estimated by summing the minutes per week of participation in sports or exercise with a MET value $\geq 3.5$. Minutes per week of leisure-time MVPA was heavily right skewed (46.9 \% of participants reported 0 min of leisuretime MVPA). Accordingly, MVPA was expressed as a categorical variable to account for its non-normal distribution. Consistent with the American Heart Association's "Life's Simple seven" metric, participants were stratified as having poor ( $0 \mathrm{~min}$ of MVPA/week), moderate ( $>0$ and $<150 \mathrm{~min}$ of MVPA/week and $>0$ and $<75$ min of vigorous physical activity/week), or ideal ( $\geq 150 \mathrm{~min}$ of MVPA/week or $\geq 75 \mathrm{~min}$ of vigorous physical activity/week) levels of leisure-time MVPA [26]. Summary measures derived from the sport and exercise-related items of the JHS physical activity survey have been validated against MVPA objectively-measured by accelerometry $(\mathrm{rho}=0.24)$ and have high reproducibility (intraclass correlation coefficient $=0.99)[27]$.

\section{Carotid ultrasonography}

An electrocardiography-gated, B-mode, and spectral steered Doppler with an integrated recorder ultrasound machine was used to obtain the carotid artery images in a $7.5 \mathrm{MHz}$ linear-array transducer [16]. Images were obtained bilaterally at the far and near walls on three segments of the carotid artery: (1) the common carotid artery (CCA), (2) bifurcation of the carotid artery, and (3) internal carotid artery. All segments were imaged from the optimal angle (the angle of interrogation that most clearly shows the separation of the internal and external carotid arteries and the tip of the flow divider). The observed values were obtained for each segment, side, and wall. For each segment, sequences of 150 consecutive frames over approximately five cardiac cycles were digitized. The widest diameter frame during systole was then selected for measurement based on visualization of arterial interfaces. Maximum likelihood estimates were calculated by adjusting for missing data in the collecting, processing, and reading of carotid images. CCA intima media thickness (CIMT) represented a maximum likelihood estimate of the average values across the right and left CCA far wall.

\section{Covariates}

Sociodemographic characteristics (age, sex, education, income, employment status), selected CVD risk factors (body mass index [BMI], diabetes, hypertension, cholesterol [total, LDL, and HDL]), lifestyle behaviors (cigarette smoking, alcohol consumption, energy intake, physical activity), estimated glomerular filtration rate (eGFR), self-reported history of myocardial infarction, and statin use were included as covariates. A detailed summary of methodology for these variables are reported in Additional file 1.

\section{Statistical analyses}

The current analysis was restricted to 3419 participants with complete data for TV viewing, occupational sitting/ standing, and CIMT. Participants who either simultaneously reported sitting and standing at work as 'never' or reported both sitting and standing at work as 'always' were excluded $(n=9)$, leaving a final sample size of 3410. Characteristics of participants included and excluded from analyses are presented in Additional file 1: Table S1.

For analyses of TV viewing, participants were grouped as follows: <2, 2-4, and $>4 \mathrm{~h} /$ day. Linear regression models were used to evaluate the association of TV viewing time with CIMT. Unadjusted regression models were first assessed modeling TV viewing (2-4 h/day and $>4 \mathrm{~h} /$ day) as indicator variables with TV viewing time $<2 \mathrm{~h}$ /day serving as the referent. Subsequent models included adjustment for age and sex (model 1), further adjustment for education less than high school, annual family income $<\$ 50,000$, fulltime employment, heavy alcohol consumption, current smoking, energy intake, history of myocardial infarction, and statin use (model 2), additional adjustment for diabetes, hypertension, BMI, total cholesterol, HDL cholesterol, LDL cholesterol, and eGFR $<60 \mathrm{ml} / \mathrm{min} / 1.73 \mathrm{~m}^{2}$ (model 3), and finally adjustment for MVPA category (model 4) and occupational sitting (model 5). Pairwise comparisons and linear trends across TV viewing categories were evaluated. The above analyses were then repeated in a fully adjusted model testing interactions for age $(<60$ and $\geq 60$ years), sex (male and female), and MVPA category (poor, moderate, or ideal) by including an interaction term in the regression model. To account for missing data among covariates, all multivariate models included only cases with complete covariate data in the most adjusted model (e.g., model 5).

All of the above analyses were repeated to examine the association of occupational sitting and, separately, occupational standing with CIMT (with adjustment for TV viewing in the most adjusted model [model 5]). For both occupational sitting and standing, participants were grouped as sitting/standing 'never or seldom', 'sometimes', and 'often or always', with 'never or seldom' serving as the 
referent. Data analyses were conducted using SPSS version 22 (SPSS Inc, Chicago, IL).

\section{Ethics, consent and permissions}

The JHS adhered to the guidelines set forth by the Declaration of Helsinki and was approved by institutional review boards of participating institutions. All participants provided informed consent.

\section{Results}

\section{Participant characteristics}

Among the 3410 participants available for analysis, 1111 (32.6\%), 1247 (36.6\%), and 1052 (30.9\%) participants watched TV $<2 \mathrm{~h} /$ day, $2-4 \mathrm{~h} /$ day, and $>4 \mathrm{~h} /$ day, respectively. Participants who reported longer daily TV viewing were, on average, older, more likely to have an annual family income $<\$ 50,000$ and less likely to complete high school and be full-time employed (Table 1).

For occupational sitting, 945 (27.7 \%), 988 (29.0\%), and 1477 (43.3\%) participants reported sitting at work 'never or seldom', 'sometimes', or 'often or always', respectively. Participants sitting at work were, on average, younger, more likely to be full-time employed, and less likely to be using statins (Additional file 1: Table S2). Participant characteristics across occupational standing categories are presented in Additional file 1: Table S3.

\section{TV Viewing and CIMT}

In unadjusted models, longer daily TV viewing was associated with greater CIMT (Table 2). This association

Table 1 Characteristics of JHS participants $(n=3410)$ by category of television viewing

\begin{tabular}{|c|c|c|c|c|}
\hline \multirow{3}{*}{ Variable } & \multicolumn{3}{|c|}{ Television viewing } & \multirow{3}{*}{ P-Trend } \\
\hline & $<2$ h/day & 2-4 h/day & $>4$ h/day & \\
\hline & $(n=1111)$ & $(n=1247)$ & $(n=1052)$ & \\
\hline Age (years) & $52.8 \pm 12.7$ & $53.2 \pm 12.4$ & $54.7 \pm 13.1$ & $<0.001$ \\
\hline Male sex (\%) & 36.5 & 37.4 & 37.8 & 0.534 \\
\hline Education < HS (\%) & 15.4 & 16.5 & 20.3 & 0.003 \\
\hline Income $<\$ 50,000(\%)$ & 68.0 & 67.0 & 72.6 & 0.023 \\
\hline Fulltime Employment (\%) & 56.8 & 57.6 & 50.9 & 0.006 \\
\hline Heavy alcohol drinking (\%) & 4.0 & 4.1 & 3.2 & 0.330 \\
\hline Current Smoking (\%) & 13.6 & 11.4 & 13.8 & 0.945 \\
\hline Energy Intake (kcal/d) & $2235.5 \pm 1360.6$ & $2228.1 \pm 1229.8$ & $2209.5 \pm 1227.9$ & 0.890 \\
\hline History of MI (\%) & 4.9 & 4.6 & 4.9 & 0.934 \\
\hline Statin Use (\%) & 10.5 & 10.6 & 12.1 & 0.245 \\
\hline Diabetes $(\%)^{b}$ & 18.3 & 19.2 & 21.4 & 0.069 \\
\hline Hypertension $(\%)^{c}$ & 55.4 & 60.8 & 59.3 & 0.058 \\
\hline BMI $\left(\mathrm{kg} / \mathrm{m}^{2}\right)$ & $31.5 \pm 7.0$ & $32.1 \pm 7.4$ & $31.8 \pm 7.6$ & 0.133 \\
\hline Obese (\%) & 51.6 & 56.5 & 52.6 & 0.579 \\
\hline Total Cholesterol (mg/dL) & $197.6 \pm 39.5$ & $199.0 \pm 41.5$ & $201.0 \pm 40.3$ & 0.178 \\
\hline HDL Cholesterol (mg/dL) & $51.9 \pm 14.6$ & $51.4 \pm 14.4$ & $51.5 \pm 14.5$ & 0.638 \\
\hline LDL Cholesterol (mg/dL) & $125.9 \pm 37.4$ & $126.3 \pm 36.9$ & $129.0 \pm 36.6$ & 0.139 \\
\hline $\mathrm{eGFR}<60 \mathrm{ml} / \mathrm{min} / 1.73 \mathrm{~m}^{2}(\%)$ & 5.6 & 5.0 & 6.2 & 0.559 \\
\hline Leisure-time MVPA (min/week) & $72.6 \pm 117.0$ & $70.4 \pm 112.6$ & $67.2 \pm 111.3$ & 0.547 \\
\hline Level of MVPA (\%) & & & & 0.265 \\
\hline Poor & 45.9 & 45.8 & 49.2 & \\
\hline Intermediate & 33.1 & 33.5 & 30.2 & \\
\hline |deal & 21.0 & 20.7 & 20.5 & \\
\hline
\end{tabular}

Data presented as mean \pm standard deviation or percentage

$H D L$ high density lipoprotein, HS high school, MI myocardial infarction, MVPA moderate to vigorous physical activity

${ }^{a}$ Defined as $>14$ drinks/week for men; $>7$ drinks/week for women

${ }^{\mathrm{b}}$ Defined as fasting glucose $\geq 126 \mathrm{mg} / \mathrm{dL}, \mathrm{HbA} 1 \mathrm{c} \geq 6.5 \%$, or use of diabetic medication

'Defined as blood pressure $\geq 140 / 90 \mathrm{mmHg}$ and/or use of antihypertensive medication

${ }^{\mathrm{d}}$ Defined according to American Heart Association Life's Simple 7 criteria for minutes/week of moderate or vigorous physical activity. Poor physical activity: 0 min/week of leisure-time moderate or vigorous physical activity. Intermediate physical activity: $>0$ and $<150$ min/week of leisure-time moderate physical activity; and $>0$ and $<75 \mathrm{~min} /$ week of leisure-time vigorous physical activity. Ideal physical activity: $\geq 150 \mathrm{~min} /$ week of leisure-time moderate physical activity; or $\geq 75$ min/week of leisure-time vigorous physical activity 
Table 2 Differences in CIMT associated with television viewing categories

\begin{tabular}{|c|c|c|c|c|c|c|}
\hline & \multicolumn{3}{|c|}{ Television viewing } & \multirow[b]{3}{*}{ P1 } & \multirow[b]{3}{*}{ P2 } & \multirow[b]{3}{*}{ P-Trend } \\
\hline & $<2$ h/day & 2-4 h/day & $>4$ h/day & & & \\
\hline & $(n=1417)$ & $(n=1699)$ & $(n=1885)$ & & & \\
\hline CIMT (mm) & $0.715 \pm 0.187$ & $0.726 \pm 0.184$ & $0.749 \pm 0.195$ & & & \\
\hline Unadjusted & 1 (ref) & $0.010 \pm 0.007$ & $0.027 \pm 0.008$ & 0.192 & $<0.001$ & $<0.001$ \\
\hline Model 1 & 1 (ref) & $0.009 \pm 0.008$ & $0.028 \pm 0.009$ & 0.287 & 0.001 & 0.001 \\
\hline Model 2 & 1 (ref) & $0.008 \pm 0.008$ & $0.028 \pm 0.009$ & 0.307 & 0.001 & 0.001 \\
\hline Model 3 & 1 (ref) & $0.009 \pm 0.008$ & $0.028 \pm 0.009$ & 0.275 & 0.001 & 0.001 \\
\hline Model 4 & 1 (ref) & $0.009 \pm 0.008$ & $0.028 \pm 0.009$ & 0.273 & 0.001 & 0.001 \\
\hline Model 5 & 1 (ref) & $0.009 \pm 0.008$ & $0.028 \pm 0.009$ & 0.258 & 0.001 & 0.001 \\
\hline
\end{tabular}

Data presented as mean \pm standard deviation or unadjusted/adjusted mean difference compared to referent group ( $<2 \mathrm{~h} /$ day) \pm standard error

$\mathrm{P} 1=2-4 \mathrm{~h} /$ day vs. $<2 \mathrm{~h} /$ day (ref); $\mathrm{P} 2=>4 \mathrm{~h} /$ day vs. $<2 \mathrm{~h} /$ day (ref)

CIMT carotid intima-media thickness

Model 1: Adjusted for age and sex

Model 2: Adjusted for covariates in model 1 plus education $<$ high school, income $<\$ 50,000$, fulltime employment, heavy alcohol drinking, current smoking, energy intake, history of myocardial infarction, and statin use

Model 3: Adjusted for covariates in model 2 plus diabetes, hypertension, BMl, total cholesterol, HDL cholesterol, LDL cholesterol, and estimated glomerular filtration rate $<60 \mathrm{ml} / \mathrm{min} / 1.73 \mathrm{~m}^{2}$

Model 4: Adjusted for covariates in model 3 plus levels of moderate to vigorous physical activity (poor, intermediate, or ideal)

Model 5: Adjusted for covariates in model 4 plus occupational sitting category (never/seldom, sometimes, or often/always)

remained statistically significant in all adjusted models (models 1-5, Table 2). The association between TV viewing and CIMT did not vary by age, sex, or MVPA category (all interaction $p$-values $>0.05$; data not shown).

\section{Occupational sitting and CIMT}

In unadjusted models, more frequent occupational sitting was associated with lower CIMT (Table 3, Upper Panel). This association remained statistically significant in all adjusted models (models $1-5$, Table 3 ). The association between occupational sitting and CIMT did not vary by age, sex, or MVPA category (all interaction $p$-values $>0.05$; data not shown).

\section{Occupational standing and CIMT}

In unadjusted and adjusted models, occupational standing was not associated with CIMT (Table 3, Lower Panel).

\section{Discussion}

In this community-based sample of African Americans, longer daily TV viewing, a leisure-time sedentary behavior, was associated with greater CIMT in adjusted models that included leisure-time MVPA level and CVD risk factors. In contrast, more frequent occupational sitting, a non-leisure time sedentary behavior, was associated with lower CIMT. These results suggest the association between sedentary behaviors and subclinical atherosclerosis in African Americans varies by leisure- and nonleisure types of sedentary behavior.

A meta-analysis of observational prospective studies has shown that TV viewing is associated with an increased risk of type 2 diabetes, fatal and non-fatal cardiovascular events, and all-cause mortality [28]. Our findings confirm the association of longer TV viewing with CVD risk and provide some of the first available data linking TV viewing to CIMT, a phenotype of early atherosclerosis. This finding may provide insight into one of the biologic pathways (i.e., early vascular changes) through which sedentary behavior may lead to CVD outcomes. Previous findings from a population-based study of 1778 white adults free of CVD risk factors who were enrolled in the National Heart, Lung, and Blood Institute Family Heart Study showed no significant association between daily TV viewing time and CIMT [29]. The null findings observed in the Family Heart Study could, in part, be attributed to the lower daily TV viewing time in the study sample, as the majority of participants (two-thirds) reported watching TV $\leq 2 \mathrm{~h} /$ day, a level that meta-analysis data suggest does not increase risk for some health outcomes [28]. In contrast, the level of TV viewing in the JHS sample was markedly higher as $71 \%$ of participants watched TV $\geq 2 \mathrm{~h} /$ day. Racial differences in the study samples (white vs. African American) and the exclusion of participants with established CVD risk factors (diabetes, hypertension, and hypercholesterolemia) in the Family Heart Study may also be contributing factors to the divergent findings between the two studies.

The association between daily TV viewing and CIMT in the JHS sample also provides evidence to implicate TV viewing as a CVD risk factor among African Americans. These findings are consistent with a recent study by Matthews et al. which demonstrated an association between longer TV viewing and higher risk for all-cause mortality among 63,308 African Americans in the Southern Community Cohort Study [11]. In contrast, sedentary screen time (combined TV viewing and computer use) was not associated with left ventricular structure and function 
Table 3 Differences in CIMT associated with occupational sitting (upper panel) and occupational standing (lower panel) categories

\begin{tabular}{|c|c|c|c|c|c|c|}
\hline & \multicolumn{3}{|c|}{ Occupational sitting } & \multirow[b]{3}{*}{ P1 } & \multirow[b]{3}{*}{ P2 } & \multirow[b]{3}{*}{ P-Trend } \\
\hline & Never or seldom & Sometimes & Often or always & & & \\
\hline & $(n=945)$ & $(n=988)$ & $(n=1477)$ & & & \\
\hline CIMT (mm) & $0.728 \pm 0.187$ & $0.706 \pm 0.174$ & $0.711 \pm 0.183$ & & & \\
\hline Unadjusted & 1 (ref) & $-0.022 \pm 0.008$ & $-0.017 \pm 0.008$ & 0.009 & 0.029 & 0.049 \\
\hline Model 1 & 1 (ref) & $-0.021 \pm 0.009$ & $-0.020 \pm 0.008$ & 0.021 & 0.017 & 0.027 \\
\hline Model 2 & 1 (ref) & $-0.021 \pm 0.009$ & $-0.019 \pm 0.008$ & 0.020 & 0.020 & 0.031 \\
\hline Model 3 & 1 (ref) & $-0.021 \pm 0.009$ & $-0.019 \pm 0.008$ & 0.019 & 0.021 & 0.033 \\
\hline Model 4 & 1 (ref) & $-0.021 \pm 0.009$ & $-0.019 \pm 0.008$ & 0.019 & 0.021 & 0.033 \\
\hline \multirow[t]{4}{*}{ Model 5} & 1 (ref) & $-0.021 \pm 0.009$ & $-0.018 \pm 0.008$ & 0.020 & 0.026 & 0.042 \\
\hline & \multicolumn{3}{|c|}{ Occupational standing } & & & \\
\hline & Never or seldom & Sometimes & Often or always & & & \\
\hline & $(n=537)$ & $(n=1153)$ & $(n=1720)$ & P1 & P2 & P-Trend \\
\hline CIMT (mm) & $0.716 \pm 0.188$ & $0.716 \pm 0.182$ & $0.712 \pm 0.180$ & & & \\
\hline Unadjusted & 1 (ref) & $0.000 \pm 0.009$ & $-0.004 \pm 0.009$ & 0.995 & 0.617 & 0.520 \\
\hline Model 1 & 1 (ref) & $0.006 \pm 0.010$ & $0.005 \pm 0.010$ & 0.543 & 0.598 & 0.699 \\
\hline Model 2 & 1 (ref) & $0.006 \pm 0.010$ & $0.005 \pm 0.010$ & 0.563 & 0.637 & 0.741 \\
\hline Model 3 & 1 (ref) & $0.006 \pm 0.010$ & $0.005 \pm 0.010$ & 0.593 & 0.631 & 0.717 \\
\hline Model 4 & 1 (ref) & $0.005 \pm 0.010$ & $0.005 \pm 0.010$ & 0.601 & 0.643 & 0.730 \\
\hline Model 5 & 1 (ref) & $0.006 \pm 0.010$ & $0.004 \pm 0.010$ & 0.584 & 0.658 & 0.758 \\
\hline
\end{tabular}

Data presented as mean \pm standard deviation or unadjusted/adjusted mean difference compared to referent group $(<2 \mathrm{~h} /$ day $) \pm$ standard error

P1 = Sometimes vs. Never of Seldom; P2 = Often or Always vs. Never or Seldom

CIMT carotid intima-media thickness

Model 1: Adjusted for age and sex

Model 2: Adjusted for covariates in model 1 plus education $<$ high school, income $<\$ 50,000$, fulltime employment, heavy alcohol drinking, current smoking, energy intake, history of myocardial infarction, and statin use

Model 3: Adjusted for covariates in model 2 plus diabetes, hypertension, BMI, total cholesterol, HDL cholesterol, LDL cholesterol, and estimated glomerular filtration rate $<60 \mathrm{ml} / \mathrm{min} / 1.73 \mathrm{~m}^{2}$

Model 4: Adjusted for covariates in model 3 plus levels of moderate to vigorous physical activity (poor, intermediate, or ideal)

Model 5: Adjusted for covariates in model 4 plus television viewing category $(<2,2-4$, or $>4 \mathrm{~h} /$ day $)$

among 1327 young African Americans in the CARDIA study [8]. Similarly, a lack of association between accelerometer-measured sedentary time and CVD risk factors was reported among 835 African Americans in the NHANES survey [9]. Reasons for the discrepant findings could, in part, be attributed to differences in sample characteristics, CVD-related outcomes, and the type of sedentary behavior measured. Notably, it has been demonstrated that self-reported sedentary behavior, in particular self-reported TV viewing, is more consistently associated with CVD risk than objective measurements of sedentary behavior [30]. Between-study differences, however, should be interpreted cautiously when comparing TV viewing time to objectivelymeasured sedentary time as TV viewing represents one type of sedentary behavior in a single domain (leisure time) while objectively-measured sedentary time comprises behavior across all domains.

In the current study, the finding that frequent occupational sitting was associated with lower CIMT adds to a growing body of literature which has previously reported either a lack of or inverse association between occupational sitting and CVD risk. A systematic review showed that of 43 identified studies, 20 reported a null finding between occupational sitting and health outcomes/conditions and five reported a decreased risk with greater occupational sitting [31]. Similar to our discrepant findings for TV viewing and occupational sitting, data from the 1958 British Birth Cohort ( $97 \%$ whites and $3 \%$ non-whites) showed differential associations of TV viewing and occupational sitting with 5 year gain in BMI. In that landmark study, higher levels of TV viewing were associated with greater positive gains in BMI, whereas more frequent occupational sitting was associated with a negative trend in BMI change [13]. Inconsistent associations for leisure-time sedentary behaviors and occupational sitting have also been reported in several other studies. Among 7660 middle-aged adults in the 1958 British Birth Cohort, higher levels of TV viewing, but not occupational sitting, had adverse associations with CVD biomarkers including C-reactive protein and fibrinogen [12]. In a Danish population-based study of 2544 adults, leisure-time sitting was adversely associated with cardio-metabolic risk factors including LDL cholesterol, 
cardiorespiratory fitness, and adiposity measures, while no significant associations were observed among these measures for occupational sitting $[14,32]$.

There are a number of possible explanations for the discrepant findings between TV viewing and occupational sitting. First, TV viewing may displace leisure-time MVPA [33, 34]. Second, the TV viewing-CVD risk association may be reflective of the lower energy expenditure of TV viewing in comparison to occupational sitting [25]. Third, the pattern of sedentary behavior may be different (e.g., prolonged, uninterrupted sedentary behavior [e.g., sitting for hours at a time] when watching TV versus more frequent and/or longer breaks from sedentary behavior at work). Finally, TV viewing is associated with increased energy-dense food and sugar-sweetened beverage consumption [35]. As laboratory-based studies have shown deleterious postprandial glucose responses during prolonged sedentary behavior, the timing of sedentary behaviors around energy-dense meals (such as during TV viewing) may be a contributing factor to the sedentary behavior-CVD risk association.

Reasons for our finding that more frequent occupational sitting is associated with lower CIMT are unclear but could, in part, be attributed to differences in white-collar vs. blue-collar work. Blue-collar workers, whom engage in less frequent occupational sitting than white-collar workers [36], consume a less healthy diet, have poorer sleep quality, and have a complex mix of work-related psychosocial factors (low job status, effort-reward imbalance, minimal health benefits, high job strain, hazardous work environment) that may contribute to the development of subclinical atherosclerosis [37, 38].

As the majority of daily sedentary time is accumulated in the workplace [39], there has been an emergence of consumer devices (sit-to-stand desks, treadmill workstations) to promote either standing or walking in the workplace as an alternative to sitting. Although the health benefits of physical activity are well established, limited empirical evidence supports standing as a means for interrupting periods of sedentary behavior. In the present study, more frequent occupational standing was not associated with lower CIMT. Occupational standing was also not associated with a reduced risk for obesity or type two diabetes in the Nurses' Health Study [40]. In contrast, greater daily time spent standing (pooling leisure- and non-leisure domains) has been reported to be associated with a lower risk for CVD and all-cause mortality in a national cohort of Canadian adults [41]. Future studies are needed to confirm if standing renders cardiovascular benefits and whether any potential health benefits from standing vary by leisure and non-leisure domains.

There are several strengths to our study. First, the JHS is one of the largest community-based studies ever conducted among African Americans. This landmark study provided a unique opportunity to characterize a modifiable risk factor (sedentary behavior) in African Americans that may be amenable to behavioral intervention. Second, sedentary behaviors that occur in two different domains (leisure and non-leisure) were assessed, whereas many previous studies only focused on types of sedentary behavior in a single or combined domain. Finally, CIMT, an indicator of subclinical atherosclerosis, was measured by trained technicians using a standardized protocol with strict quality control procedures.

Several limitations must also be noted when interpreting our findings. First, sedentary behavior was measured by self-report. However, self-report questionnaires can provide information about sedentary behavior in specific domains (e.g., leisure- and non-leisure) which are not available from objectively measured data. Second, questions on TV viewing and occupational sitting had different response formats: for TV viewing, participants responded using pre-defined duration categories of hours/day or week (e.g., 1-2 h/day); for occupational sitting, participants responded using pre-defined frequency categories (e.g., 'never', 'seldom'). Thus, the difference in measurement precision for assessing TV viewing and occupational sitting may have affected our study findings. Third, the JHS was conducted in a single metropolitan area in the Southeastern US, possibly limiting its generalizability to other African American populations. Fourth, although we controlled for many potentially confounding variables that could account for the discrepant findings between TV viewing and occupational sitting, there may be residual confounding from unmeasured factors. Finally, because of the cross-sectional nature of our analyses, we cannot infer causality.

\section{Conclusions}

In this community-based sample of African Americans the association between sedentary behavior and subclinical atherosclerosis varied by TV viewing and occupational sitting. These data provide evidence that leisure-based sedentary behavior, in particular TV viewing, is associated with higher CIMT in African Americans. In contrast, more frequent occupational sitting was associated with lower CIMT in our study sample. Future research may be warranted to determine whether TV viewing is a potential target for behavioral intervention to mitigate CVD risk among African Americans. Elucidating factors that contribute to the differential associations of leisure and non-leisure types of sedentary behavior with CVD risk (e.g., Does the way sedentary behavior is patterned [sitting for hours at a time] carry any clinical significance beyond the total volume of sedentary time? Is the timing of sedentary behavior around energy-dense meals more harmful?) may also be warranted to inform future physical activity guidelines. 


\section{Additional files}

Additional file 1: Supplemental Methods. Supplemental References. Table S1. Characteristics of JHS participants included and not included from analyses. Table S2. Characteristics of Jackson Heart Study participants ( $n=3410$ ) by category of occupational sitting. Table S3. Characteristics of Jackson Heart Study participants $(n=3410)$ by category of occupational standing. (DOCX $45 \mathrm{~kb}$ )

\section{Competing interests}

The authors declare they have no competing interests.

\section{Authors' contributions}

KMD, PM, and DS conceived the manuscript. MS and PMD participated in the design of the study and data collection. KMD performed the statistical analyses in consultation with SRS. KMD drafted the manuscript. JNB III, SRS, $\mathrm{SPH}, \mathrm{MS}, \mathrm{PMD}, \mathrm{PM}$, and DS critically revised the manuscript. All authors read and approved the final manuscript

\section{Acknowledgements}

The Jackson Heart Study is supported by contracts HHSN268201300046C, HHSN268201300047C, HHSN268201300048C, HHSN268201300049C, HHSN268201300050C from the National Heart, Lung, and Blood Institute (NHLBI) and the National Institute on Minority Health and Health Disparities (NIMHD). This work was also supported by R01-HL117323 from NHLBI/NIH and an NHLBI/NIH Diversity Supplement awarded to KM Diaz (R01-HL116470-02S1). This manuscript has been reviewed by the Jackson Heart Study for scientific content and consistency of data interpretation with previous JHS publications. The authors would like to give a sincere thank you to the Jackson Heart Study participants, investigators, and staff for their valuable contributions and long-term commitment to the study.

\section{Author details}

${ }^{1}$ Department of Medicine, Center for Behavioral Cardiovascular Health, Columbia University Medical Center, 622 West 168th Street, PH9-319, New York, NY 10032, USA. ²Department of Epidemiology, School of Public Health, University of Alabama at Birmingham, Birmingham, AL, USA. ${ }^{3}$ Center of Biostatistics and Bioinformatics, University of Mississippi Medical Center, Jackson, MS, USA. ${ }^{4}$ School of Nutrition and Health Promotion, Arizona State University, Phoenix, AZ, USA. ${ }^{5}$ Department of Medicine, University of Mississippi Medical Center, Jackson, MS, USA. ${ }^{6}$ South Central Mental Illness, Research, and Clinical Center and Little Rock Geriatric Research, Education, and Clinical Center, Little Rock, AR, USA.

\section{Received: 12 August 2015 Accepted: 12 February 2016}

\section{Published online: 01 March 2016}

\section{References}

1. Mozaffarian D, Benjamin EJ, Go AS, Arnett DK, Blaha MJ, Cushman M, et al. Heart disease and stroke statistics-2015 update: a report from the american heart association. Circulation. 2015;131(4):e29-e322.

2. National Center for Health Statistics. Health, United States, 2013: with special feature on prescription drugs. Hyattsville: National Center for Health Statistics; 2014. p. 8-9.

3. Siegel R, Ma J, Zou Z, Jemal A. Cancer statistics, 2014. CA Cancer J Clin. 2014;64(1):9-29.

4. Ford ES, Ajani UA, Croft JB, Critchley JA, Labarthe DR, Kottke TE, et al. Explaining the decrease in U.S. deaths from coronary disease, 1980-2000. N Engl J Med. 2007;356(23):2388-98.

5. Orsi JM, Margellos-Anast H, Whitman S. Black-White health disparities in the United States and Chicago: a 15-year progress analysis. Am J Public Health. 2010;100(2):349-56.

6. Dunstan DW, Howard B, Healy GN, Owen N. Too much sitting-a health hazard. Diabetes Res Clin Pract. 2012;97(3):368-76.

7. Owen N, Healy GN, Matthews CE, Dunstan DW. Too much sitting: the population health science of sedentary behavior. Exerc Sport Sci Rev. 2010;38(3):105-13.

8. Gibbs BB, Reis JP, Schelbert EB, Craft LL, Sidney S, Lima J, et al. Sedentary screen time and left ventricular structure and function: the CARDIA study. Med Sci Sports Exerc. 2014;46(2):276-83.
9. Healy GN, Matthews CE, Dunstan DW, Winkler EA, Owen N. Sedentary time and cardio-metabolic biomarkers in US adults: NHANES 2003-06. Eur Heart J. 2011;32(5):590-7.

10. Lowry R, Wechsler H, Galuska DA, Fulton JE, Kann L. Television viewing and its associations with overweight, sedentary lifestyle, and insufficient consumption of fruits and vegetables among US high school students: differences by race, ethnicity, and gender. J Sch Health. 2002;72(10):413-21.

11. Matthews CE, Cohen SS, Fowke JH, Han X, Xiao Q, Buchowski MS, et al. Physical activity, sedentary behavior, and cause-specific mortality in black and white adults in the Southern Community Cohort Study. Am J Epidemiol. 2014;180(4):394-405.

12. Pinto Pereira SM, Ki M, Power C. Sedentary behaviour and biomarkers for cardiovascular disease and diabetes in mid-life: the role of televisionviewing and sitting at work. PLoS One. 2012;7(2):e31132.

13. Pinto Pereira SM, Power C. Sedentary behaviours in mid-adulthood and subsequent body mass index. PLoS One. 2013;8(6):e65791.

14. Saidj M, Jorgensen T, Jacobsen RK, Linneberg A, Aadahl M. Differential cross-sectional associations of work- and leisure-time sitting, with cardiorespiratory and muscular fitness among working adults. Scand J Work Environ Health. 2014;40(5):531-8.

15. Stamatakis E, Chau JY, Pedisic Z, Bauman A, Macniven R, Coombs N, et al, Are sitting occupations associated with increased all-cause, cancer, and cardiovascular disease mortality risk? A pooled analysis of seven British population cohorts. PLoS One. 2013;8(9):e73753.

16. Carpenter MA, Crow R, Steffes M, Rock W, Heilbraun J, Evans G, et al. Laboratory, reading center, and coordinating center data management methods in the Jackson Heart Study. Am J Med Sci. 2004;328(3):131-44.

17. Fuqua SR, Wyatt SB, Andrew ME, Sarpong DF, Henderson FR, Cunningham $M F$, et al. Recruiting African-American research participation in the Jackson Heart Study: methods, response rates, and sample description. Ethn Dis. 2005;15(4 Suppl 6):S6. -18-29.

18. Payne TJ, Wyatt SB, Mosley TH, Dubbert PM, Guiterrez-Mohammed ML, Calvin RL, et al. Sociocultural methods in the Jackson Heart Study: conceptual and descriptive overview. Ethn Dis. 2005;15(4 Suppl 6):S6. -38-48.

19. Taylor Jr HA, Wilson JG, Jones DW, Sarpong DF, Srinivasan A, Garrison RJ, et al. Toward resolution of cardiovascular health disparities in African Americans: design and methods of the Jackson Heart Study. Ethn Dis. 2005;15(4 Suppl 6):S6. -4-17.

20. Dubbert PM, Carithers T, Ainsworth BE, Taylor Jr HA, Wilson G, Wyatt SB. Physical activity assessment methods in the Jackson Heart Study. Ethn Dis. 2005;15 suppl 6:S6. -56-S6-61.

21. Clark BK, Healy GN, Winkler EA, Gardiner PA, Sugiyama T, Dunstan DW, et al. Relationship of television time with accelerometer-derived sedentary time: NHANES. Med Sci Sports Exerc. 2011;43(5):822-8.

22. Wareham NJ, Jakes RW, Rennie KL, Mitchell J, Hennings S, Day NE. Validity and repeatability of the EPIC-Norfolk physical activity questionnaire. Int J Epidemiol. 2002;31(1):168-74.

23. Wijndaele K, DE Bourdeaudhuij I, Godino JG, Lynch BM, Griffin SJ, Westgate $\mathrm{K}$, et al. Reliability and validity of a domain-specific last 7-d sedentary time questionnaire. Med Sci Sports Exerc. 2014;46(6):1248-60.

24. Bell EJ, Lutsey PL, Windham BG, Folsom AR. Physical activity and cardiovascular disease in African Americans in Atherosclerosis risk in communities. Med Sci Sports Exerc. 2013;45(5):901-7.

25. Ainsworth BE, Haskell WL, Whitt MC, Irwin ML, Swartz AM, Strath SJ, et al. Compendium of physical activities: an update of activity codes and MET intensities. Med Sci Sports Exerc. 2000;32(9 Suppl):S498-504.

26. Lloyd-Jones DM, Hong Y, Labarthe D, Mozaffarian D, Appel LJ, Van Horn $L$, et al. Defining and setting national goals for cardiovascular health promotion and disease reduction: the American Heart Association's strategic impact goal through 2020 and beyond. Circulation. 2010;121(4):586-613.

27. Smitherman TA, Dubbert PM, Grothe KB, Sung JH, Kendzor DE, Reis JP, et al. Validation of the Jackson Heart Study physical activity survey in African Americans. J Phys Act Health. 2009;6 Suppl 1:S124-32.

28. Grontved A, Hu FB. Television viewing and risk of type 2 diabetes, cardiovascular disease, and all-cause mortality: a meta-analysis. JAMA. 2011;305(23):2448-55.

29. Kronenberg F, Pereira MA, Schmitz MK, Arnett DK, Evenson KR, Crapo RO, et al. Influence of leisure time physical activity and television watching on atherosclerosis risk factors in the NHLBI Family Heart Study. Atherosclerosis. 2000;153(2):433-43. 
30. Stamatakis E, Hamer M, Tilling K, Lawlor DA. Sedentary time in relation to cardio-metabolic risk factors: differential associations for self-report vs accelerometry in working age adults. Int J Epidemiol. 2012;41(5):1328-37.

31. van Uffelen JG, Wong J, Chau JY, van der Ploeg HP, Riphagen I, Gilson ND, et al. Occupational sitting and health risks: a systematic review. Am J Prev Med. 2010;39(4):379-88.

32. Saidj M, Jorgensen T, Jacobsen RK, Linneberg A, Aadahl M. Separate and joint associations of occupational and leisure-time sitting with cardiometabolic risk factors in working adults: a cross-sectional study. PLoS One. 2013;8(8):e70213.

33. Tucker LA, Bagwell M. Television viewing and obesity in adult females. Am J Public Health. 1991;81 (7):908-11.

34. Tucker LA, Friedman GM. Television viewing and obesity in adult males. Am J Public Health. 1989;79(4):516-18.

35. Pearson N, Biddle SJ. Sedentary behavior and dietary intake in children, adolescents, and adults. A systematic review. Am J Prev Med. 2011:41(2):178-88.

36. Mummery WK, Schofield GM, Steele R, Eakin EG, Brown WJ. Occupational sitting time and overweight and obesity in Australian workers. Am J Prev Med. 2005;29(2):91-7.

37. Clougherty JE, Souza K, Cullen MR. Work and its role in shaping the social gradient in health. Ann NY Acad Sci. 2010;1 186:102-24.

38. Turrell G, Hewitt B, Patterson C, Oldenburg B, Gould T. Socioeconomic differences in food purchasing behaviour and suggested implications for diet-related health promotion. J Hum Nutr Diet. 2002;15(5):355-64.

39. Jans MP, Proper Kl, Hildebrandt VH. Sedentary behavior in Dutch workers: differences between occupations and business sectors. Am J Prev Med. 2007:33(6):450-4.

40. Hu FB, Li TY, Colditz GA, Willett WC, Manson JE. Television watching and other sedentary behaviors in relation to risk of obesity and type 2 diabetes mellitus in women. JAMA. 2003;289(14):1785-91.

41. Katzmarzyk PT. Standing and mortality in a prospective cohort of Canadian adults. Med Sci Sports Exerc. 2014:46(5):940-6.

\section{Submit your next manuscript to BioMed Central} and we will help you at every step:

- We accept pre-submission inquiries

- Our selector tool helps you to find the most relevant journal

- We provide round the clock customer support

- Convenient online submission

- Thorough peer review

- Inclusion in PubMed and all major indexing services

- Maximum visibility for your research

Submit your manuscript at www.biomedcentral.com/submit
Biomed Central 